\title{
Bioanalytical Method for Pamabrom (Determined as 8-Bromotheophylline) and its Application to a Pharmacokinetic Study
}

\author{
Lucio-Maldonado S, Cruz-Salinas MA, López-Bojórquez E, Pérez-Becerril F, Burke-Fraga V, and \\ González-de la Parra $\mathbf{M}^{*}$
}

Biokinetics, S. A. de C. V., Mexico City, Mexico

${ }^{*}$ Corresponding author: González-de la Parra M, Biokinetics, S.A. de C.V., Mexico City, Mexico, E-mail: mdelaparra@biokinetics.com.mx

Citation: Lucio-Maldonado S, Cruz-Salinas MA, López-Bojórquez E, Pérez-Becerril F, Burke-Fraga V, González-de la Parra M (2017) Bioanalytical Method for Pamabrom (Determined as 8-Bromotheophylline) and its Application to a Pharmacokinetic Study. J Bioequiv Stud 3(1): 101

Received Date: January 25, 2017 Accepted Date: February 27, 2017 Published Date: March 03, 2017

\begin{abstract}
Pamabrom is a common over-the-counter mild diuretic that is often used in combination with acetaminophen and other drugs for the treatment of menstrual pain. It consists of a 1:1 ratio mixture of 8-bromotheophylline and 2-amino-2-methyl-1-propanol.

A bioanalytical method for pamabrom, determined as 8-bromotheophylline, was developed and validated using reverse-phase HPLC coupled with UV detection.

This method was found to be reliable based on its validation and it was successfully applied to a pharmacokinetic study, in which a single dose of $25 \mathrm{mg}$ of pamabrom was administered orally in combination with $300 \mathrm{mg}$ of paracetamol and $220 \mathrm{mg}$ of naproxen sodium to Mexican female subjects.
\end{abstract}

Keywords: Pamabrom; 8-bromotheophylline; Bioanalytical method; Pharmacokinetics

\section{Introduction}

Pamabrom is a mild diuretic that consist of a 1:1 ratio mixture of 8-bromotheophylline and 2-amino-2-methyl-1-propanol (Figure 1), in which 8-bromotheophylline is the active diuretic ingredient [1]. There is a hypothesis that the 2-amino-2-methyl-1-propanol may also function as a diuretic, as some alcohols act indirectly as diuretics by suppressing the release of antidiuretic hormone from the posterior pituitary gland [2]. However, we did not find any study supporting this hypothesis.

Pamabrom, a common over-the-counter diuretic, is often used in combination with acetaminophen and other drugs for the treatment menstrual pain [2,3]. For example, in a recent clinical trial, the efficacy and safety of two oral medications (with different drug combinations): a test medication containing naproxen sodium (220 mg), paracetamol (300 mg) and pamabrom (25 mg); and a reference medication containing paracetamol $(500 \mathrm{mg})$, pyrilamine (15 mg) and pamabrom ( $25 \mathrm{mg})$, were evaluated on primary dysmenorrhea in Mexican women. In this trial, it was concluded that both drug combinations were not different in reducing the dysmenorrheic pain [4].
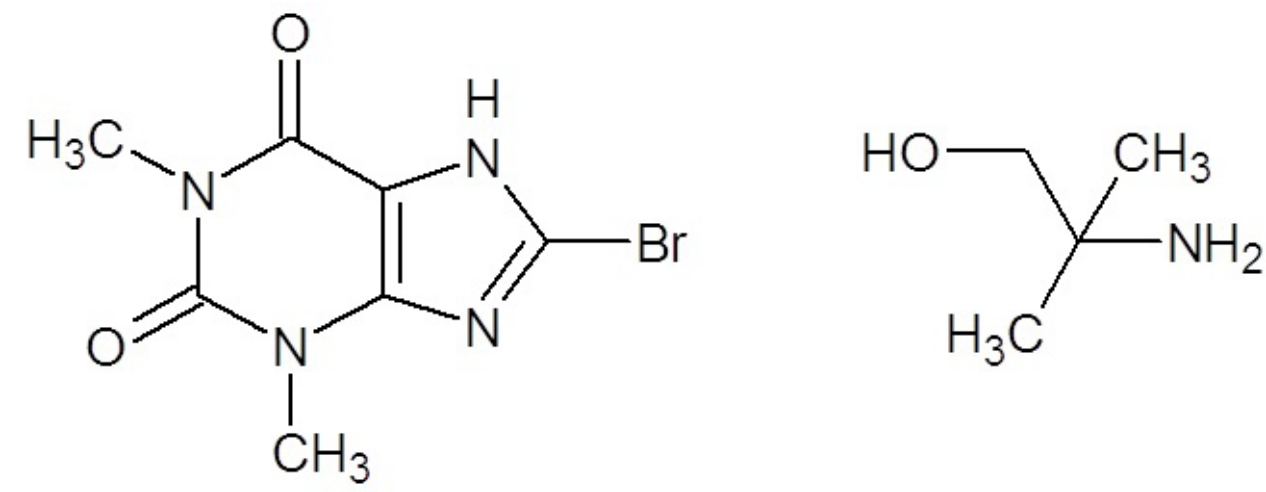

Figure 1: Chemical structures of the components of pamabrom: 8-bromotheophylline and 2-amino-2-methyl-1-propanol 
Considering the combination of pamabrom, paracetamol and naproxen sodium, there is information regarding bionalytical methods for the simultaneous determination of naproxen sodium and paracetamol in human plasma [5]. However, we found two references on bionalytical methods for the determination of pamabrom (determined as 8-bromotheophylline) in combination with only paracetamol in human plasma [6,7].

Therefore, the aim of this research was to develop and validate a bioanalytical method for pamabrom, determined as 8-bromotheophylline, in human plasma for pharmacokinetic evaluation of the oral administration of $25 \mathrm{mg}$ of pamabrom in combination with $220 \mathrm{mg}$ of naproxen sodium and $300 \mathrm{mg}$ of paracetamol in human Mexican female subjects.

\section{Material and Methods}

\section{Chemical and reagents}

Pamabrom (98\% purity) was obtained from Toronto Research Chemicals (Ontario, Canada), and the caffeine, the internal standard (IS), was obtained from USP (Rockville, MD).

All solvents (including water) were HPLC grade (Avantor Performance Materials, Inc., Phillipsburg, NJ) and all reagents were analytical grade (Mallinckrodt Baker, Inc., Phillipsburg, NJ).

Pooled blank human plasma from healthy subjects was provided by Medica Sur Hospital (Mexico City, Mexico), and stored at $-75^{\circ} \mathrm{C} \pm 5^{\circ} \mathrm{C}$ until its use.

\section{Stock solutions}

Pamabrom was determined as 8-bromotheophylline (henceforth referred to as the analyte). A stock solution of the analyte with a concentration of $500 \mu \mathrm{g} / \mathrm{mL}$ was prepared by dissolving the necessary amount of pamabrom equivalent to $2.5 \mathrm{mg}$ of 8-bromotheophylline in $5 \mathrm{~mL}$ of water.

A stock solution of the IS with a concentration of $200 \mu \mathrm{g} / \mathrm{mL}$ was prepared by dissolving $2 \mathrm{mg}$ of caffeine in $10 \mathrm{~mL}$ of water. The stock solutions were stored at $5^{\circ} \mathrm{C} \pm 3^{\circ} \mathrm{C}$ until use.

\section{Study samples, Calibration curve and QC samples}

The study samples $(250 \mu \mathrm{L})$ were spiked with $10 \mu \mathrm{L}$ of the IS solution $(100 \mu \mathrm{g} / \mathrm{mL})$.

The calibration curve consisted of 7 points with concentration levels of 20,40,100, 200, 400, 500 and $800 \mathrm{ng} / \mathrm{mL}$. Calibration samples were prepared for each point of the calibration curve using the following components: $200 \mu \mathrm{L}$ of human plasma (blank), 40 $\mu \mathrm{L}$ of water, $10 \mu \mathrm{L}$ of the corresponding stock solution of the analyte and $10 \mu \mathrm{L}$ of the IS solution $(100 \mu \mathrm{g} / \mathrm{mL})$.

The QCs (low, medium, high) and diluted samples were prepared as described for the calibration samples, at concentrations of 60 $\mathrm{ng} / \mathrm{mL}$ (LQC), $300 \mathrm{ng} / \mathrm{mL}$ (MQC), and $600 \mathrm{ng} / \mathrm{mL}$ (HQC), respectively.

\section{Sample treatment}

All samples were treated with $1000 \mu \mathrm{L}$ of a mixture of ethyl acetate and cyclohexane (90:10 v/v) and $100 \mu \mathrm{L}$ of an aqueous solution of phosphoric acid (3.8\%). The resulting mixtures were vortexed for 1 minute and then centrifuged for 5 minutes at $8000 \mathrm{rpm}$ $\left(20^{\circ} \mathrm{C}\right)$. The organic phase was transferred to a test tube where it was evaporated to dryness under a stream of nitrogen at $50^{\circ} \mathrm{C}$. The extracts were reconstituted in $100 \mu \mathrm{L}$ of methanol:water mixture $(75: 25 \mathrm{v} / \mathrm{v})$. The reconstituted solutions were then vortexed for 15 seconds. Finally, $20 \mu \mathrm{L}$ of the reconstituted solution were injected into the chromatographic system.

Although it is common practice to dissolve the dried extract in the mobile phase, the methanol and water mixture was selected because the extract has better solubility in this mixture than in the mobile phase. There were no compatibility problems with the mobile phase.

\section{Instrumentation and chromatographic conditions}

An Agilent 1200 and an Agilent 1260 were used for high-performance liquid chromatography (HPLC), both from Agilent Technologies (Palo Alto; California). Both equipments consisted of a binary pump, a high-performance degasser, a high performance autosampler, a thermostatted column compartment, and a multiple wavelength detector.

Pamabrom concentrations were determined with a column ( $150 \times 4.6-\mathrm{mm}, 5-\mu \mathrm{m}$ particle size, Zorbax ${ }^{\circ} \mathrm{SB}-\mathrm{C} 8$, Agilent Technologies, Palo Alto, California) equipped with a pre-column ( $12.5 \times$ x 4.6-mm, $5-\mu \mathrm{m}$ particle size, Zorbax ${ }^{\circ} \mathrm{SB}-\mathrm{C} 8$ (Agilent Technologies, Palo Alto, California) and eluted with a mobile phase consisting of: component A (aqueous ammonium acetate (10 mM, pH 5.0 \pm 0.1$)$ ) and component $B$ (acetonitrile:water mixture $(95: 5 \mathrm{v} / \mathrm{v})$ ) with an $\mathrm{A}: \mathrm{B}$ ratio of $83: 17 \mathrm{v} / \mathrm{v}$.

The column temperature was $15^{\circ} \mathrm{C}$, the flow rate was kept at $1 \mathrm{~mL} /$ minute, the run time was 6.5 minutes, the injection volume was $20 \mu \mathrm{L}$ and the analyte detection was carried out at a wavelength of $278 \mathrm{~nm}$. 


\section{Preparation of subject samples}

Method validation: The method was validated according to Mexican and international guidelines regarding bioanalytical method validation $[8-10]$.

The validation included selectivity, carry-over, calibration curve, lower limit of quantification; accuracy, precision; dilution integrity, and stability.

Data analysis: The calibration curves were analyzed by linear regression of the peak area ratios (analyte/IS) as a function of the analyte concentrations.

The pharmacokinetic $(\mathrm{PK})$ parameters were:

$\mathrm{C}_{\max }: \quad$ maximum plasma drug concentration,

$\mathrm{T}_{\max }$ : $\quad$ time to reach $\mathrm{C}_{\max }$,

$\mathrm{k}: \quad$ apparent terminal elimination rate constant,

$\mathrm{t}_{1 / 2}$ : apparent terminal elimination half-life,

$\mathrm{AUC}_{0-\mathrm{t}}:$ Area under the plasma concentration-time curve from zero

(0) hours to the last measurable concentration (t).

$\mathrm{AUC}_{0-\infty}$ : Area under the plasma concentration-time curve from zero

(0) hours to infinity $(\infty)$.

These were estimated using the non-compartmental approach with WinNonlin Phoenix software version 6.4.

\section{Results and Discussion}

\section{Chromatography}

Figure 2 shows several representative chromatograms obtained during the validation of the bioanalytical method.

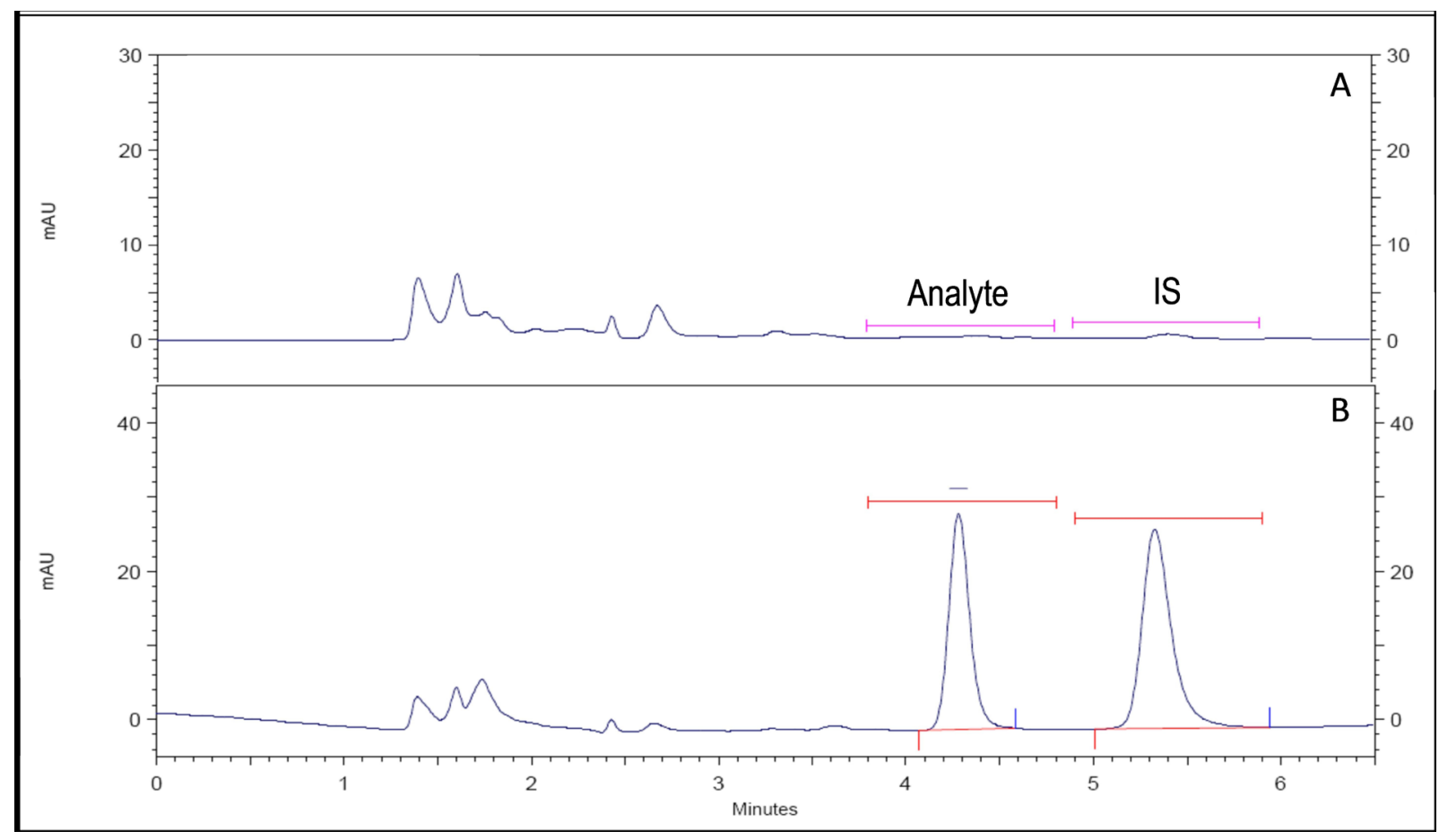

Figure 2: Representative chromatograms. .A: blank human plasma sample. B: human plasma sample spiked with the analyte $(500 \mathrm{ng} / \mathrm{mL})$ and the internal standard $(1000 \mathrm{ng} / \mathrm{mL})$

The retention times (mean \pm SD) for the analyte and the IS were $4.30 \pm 0.81$ and $5.33 \pm 1.02$ minutes, respectively.

\section{Selectivity}

The selectivity was evaluated by analyzing blank human plasma samples from six different subjects, blank human (hemolyzed and lipemic) plasma samples, anticoagulants (lithium and sodium heparin), xanthines (theobromine), and other drug substances commonly used as analgesics (acetylsalicylic acid, ibuprofen, diclofenac, paracetamol and naproxen). No interferences were observed in the resulting chromatograms. 


\section{Calibration curve, lower limit of quantification, linearity, and carry-over}

The calibration curve consisted of 7 points with concentration levels of 20,40, 100, 200, 400, 500 and $800 \mathrm{ng} / \mathrm{mL}$. Thus the range of the curve was $20 \mathrm{ng} / \mathrm{mL}$ to $800 \mathrm{ng} / \mathrm{mL}$. The lower limit of quantification (LLOQ) was $20 \mathrm{ng} / \mathrm{mL}$ and the upper limit of quantification (ULOQ) was $800 \mathrm{ng} / \mathrm{mL}$. The LLOQ was determined as the lowest concentration of the analyte in a sample which can be quantified reliably, with an acceptable accuracy and precision, which is discussed below.

The carry-over of the method was evaluated by injecting blank samples after the injection of the ULOQ sample, and no signals were detected at the expected retention times for either the analyte or the IS in the resulting chromatograms.

The linearity of the method was evaluated by analyzing the data obtained from 4 calibration curves. The corresponding slopes, intercepts, as well as the correlation and determination coefficients are shown in Table 1.

\begin{tabular}{|c|c|c|c|c|}
\hline $\begin{array}{c}\text { Calibration } \\
\text { curve }\end{array}$ & Slope (m) & Intercept $(\mathbf{b})$ & $\begin{array}{c}\text { Determination } \\
\text { coefficient }\left(\mathbf{r}^{\mathbf{2}}\right)\end{array}$ & $\begin{array}{c}\text { Correlation } \\
\text { coefficient }(\mathbf{r})\end{array}$ \\
\hline 1 & 0.00153 & -0.00711 & 0.99951 & 0.99976 \\
\hline 2 & 0.00155 & -0.00021 & 0.99954 & 0.99977 \\
\hline 3 & 0.00157 & -0.00887 & 0.99990 & 0.99995 \\
\hline 4 & 0.00155 & -0.00456 & 0.99839 & 0.99919 \\
\hline
\end{tabular}

Table 1: Linearity of the method

All of the correlation coefficients and the determination coefficients were greater than 0.99 , which supports the linearity of the method.

\section{Accuracy, precision, and dilution integrity}

The intra-day accuracy and precision of the method was evaluated by analyzing 5 replicates of LLOQ and QCs (low, medium, high).

In order to evaluate dilution integrity, two additional samples were analyzed using 5 replicates, at an initial concentration of 1000 $\mathrm{ng} / \mathrm{mL}$ (higher than the ULOQ), which were further diluted (1:2 and 1:5 dilution ratios).

In a similar manner, the inter-day accuracy and precision of the method were evaluated using 3 analytical runs by analyzing 5 replicates of LLOQ and QCs (low, medium, high).

Accuracy was expressed as the \% relative error (\%RE) between the quantified and the nominal value; and the precision was expressed as \% coefficient of variation (\%CV).

The results for the accuracy and precision of the method are summarized in Table 2 and those for the evaluation of dilution integrity are shown in Table 3.

\begin{tabular}{|c|c|c|c|c|c|c|c|}
\hline & & \multicolumn{2}{|c|}{ Intra-day } & \multicolumn{3}{c|}{ Inter-day } \\
\hline Sample & $\begin{array}{c}\text { Nominal } \\
\text { concentration }(\mathrm{ng} / \mathrm{mL})\end{array}$ & $\begin{array}{c}\text { Concentration found } \\
(\mathbf{n g} / \mathrm{mL}) \pm \text { SD }\end{array}$ & $\begin{array}{c}\text { Precision } \\
\text { CV }(\%)\end{array}$ & $\begin{array}{c}\text { Accuracy } \\
\text { RE(\%) }\end{array}$ & $\begin{array}{c}\text { Concentration found } \\
(\mathbf{n g} / \mathrm{mL}) \pm \text { SD }\end{array}$ & $\begin{array}{c}\text { Precision } \\
\text { CV }(\%)\end{array}$ & $\begin{array}{c}\text { Accuracy } \\
\text { RE }(\%)\end{array}$ \\
\hline LLOQ & 20 & $20.13 \pm 0.43$ & 2.16 & 0.67 & $20.03 \pm 2.12$ & 10.60 & 0.15 \\
\hline LQC & 60 & $60.18 \pm 0.96$ & 1.60 & 0.31 & $60.95 \pm 1.36$ & 2.23 & 1.59 \\
\hline MQC & 300 & $275.07 \pm 10.53$ & 3.83 & -8.31 & $294.85 \pm 15.98$ & 5.42 & -1.72 \\
\hline HQC & 600 & $613.97 \pm 16.95$ & 2.76 & 2.33 & $611.88 \pm 10.30$ & 1.68 & 1.98 \\
\hline
\end{tabular}

CV: coefficient of variation; RE: relative error; LLOQ: lower limit of quantification; LQC: low quality control sample, MQC: medium quality control sample, and HQC: high quality control sample

Table 2: Accuracy and precision of the method

\begin{tabular}{|c|c|c|c|c|}
\hline & & \multicolumn{3}{|c|}{ Dilution integrity } \\
\hline Sample & $\begin{array}{c}\text { Nominal } \\
\text { concentration }(\mathbf{n g} / \mathbf{m L})\end{array}$ & $\begin{array}{c}\text { Concentration found } \\
(\mathbf{n g} / \mathbf{m L}) \pm \text { SD }\end{array}$ & $\begin{array}{c}\text { Precision } \\
\text { CV (\%) }\end{array}$ & $\begin{array}{c}\text { Accuracy } \\
\text { RE (\%) }\end{array}$ \\
\hline DS 1:2 & 1000 & $974.59 \pm 66.66$ & 6.84 & -2.54 \\
\hline DS 1:5 & 1000 & $965.95 \pm 24.08$ & 2.49 & -3.41 \\
\hline \multicolumn{4}{|c|}{$\begin{array}{c}\text { CV: coefficient of variation; RE: relative error, DS diluted sample } \\
\text { Table 3: Dilution integrity evaluation }\end{array}$}
\end{tabular}

The mean \%RE results for both intra- and inter-day accuracy for all tested concentration levels were within the acceptance range of $\pm 20 \%$ of the nominal value for the LLOQ and within $\pm 15 \%$ of the nominal values for the higher concentration levels. In addition, the $\% \mathrm{CV}$ results for both intra- and inter-day precision for all tested concentration levels were less than $20 \%$ for the LLOQ, and less than $15 \%$ for the higher concentration levels [8-10]. 
For the dilution integrity evaluation, the results of this evaluation indicated that the above mentioned criteria for both accuracy and precision were also met.

The use of the HPLC equipment (Agilent 1200 and 1260) was also evaluated, and the results indicated that the accuracy and precision criteria were met in this case as well (data not provided).

\section{Stability}

The stability of the analyte was evaluated under the following conditions: freeze and thaw (3 cycles); processed sample at room temperature; evaporated sample (dry extract); in autosampler, long term stability $\left(\right.$ at $-75^{\circ} \mathrm{C} \pm 5^{\circ} \mathrm{C}$ ) and stock solutions (analyte and IS). Triplicate QCs (low and high) were used for this evaluation. The results are summarized in Table 4.

\begin{tabular}{|c|c|c|c|c|c|c|}
\hline \multirow[t]{2}{*}{ Stability } & \multicolumn{3}{|c|}{ LQC $60(\mathrm{ng} / \mathrm{mL})$} & \multicolumn{3}{|c|}{ HQC $600(\mathrm{ng} / \mathrm{mL})$} \\
\hline & $\begin{array}{l}\text { Concentration } \\
\text { found } \\
(\mathrm{ng} / \mathrm{mL}) \pm \mathrm{SD}\end{array}$ & $\begin{array}{l}\text { Precision } \\
\text { CV (\%) }\end{array}$ & $\begin{array}{l}\text { Accuracy } \\
\text { RE (\%) }\end{array}$ & $\begin{array}{l}\text { Concentration } \\
\text { found (ng/ } \\
\mathrm{mL}) \pm \mathrm{SD}\end{array}$ & $\begin{array}{l}\text { Precision } \\
\text { CV (\%) }\end{array}$ & $\begin{array}{l}\text { Accuracy } \\
\text { RE (\%) }\end{array}$ \\
\hline $\begin{array}{l}\text { Freeze and thaw } \\
\qquad(3 \text { cycles })\end{array}$ & $53.65 \pm 1.51$ & 2.82 & -10.58 & $559.03 \pm 5.64$ & 1.01 & -6.83 \\
\hline $\begin{array}{l}\text { Processed sample at } \\
\text { room temperature }(27 \mathrm{~h})\end{array}$ & $60.85 \pm 1.43$ & 2.34 & 1.42 & $586.95 \pm 15.38$ & 2.62 & -2.17 \\
\hline $\begin{array}{l}\text { Evaporated sample: dry } \\
\text { extract ( } 24 \mathrm{~h} \text { at room } \\
\text { temperature) }\end{array}$ & $56.54 \pm 1.17$ & 2.08 & -5.77 & $523.86 \pm 13.31$ & 2.54 & -12.69 \\
\hline $\begin{array}{l}\text { Long term }(16 \text { weeks at- } \\
\left.\qquad 75^{\circ} \mathrm{C} \pm 5^{\circ}\right)\end{array}$ & $66.33 \pm 1.05$ & 1.58 & 10.56 & $618.60 \pm 3.65$ & 0.59 & 3.10 \\
\hline $\begin{array}{l}\text { In autosampler ( } 74 \mathrm{~h} \text { at } \\
\text { room temperature) }\end{array}$ & $62.21 \pm 0.88$ & 1.41 & 3.69 & $575.58 \pm 9.48$ & 1.65 & -4.07 \\
\hline \multirow[t]{2}{*}{ Stability } & \multicolumn{2}{|c|}{ LQC $60(\mathrm{ng} / \mathrm{mL})$} & & \multicolumn{2}{|c|}{ HQC $600(\mathrm{ng} / \mathrm{mL})$} & \\
\hline & $\begin{array}{l}\text { Precision } \\
\text { CV (\%) }\end{array}$ & $\begin{array}{l}\text { Accuracy } \\
\text { RE (\%) }\end{array}$ & & $\begin{array}{l}\text { Precision } \\
\text { CV (\%) }\end{array}$ & $\begin{array}{l}\text { Accuracy } \\
\text { RE (\%) }\end{array}$ & \\
\hline $\begin{array}{l}\text { Stock solution: Analyte } \\
\text { standard } \\
\text { ( } 3 \text { weeks at } 5^{\circ} \mathrm{C} \pm 3^{\circ} \mathrm{C} \text { ) }\end{array}$ & 0.12 & 6.76 & & 0.29 & 2.42 & \\
\hline $\begin{array}{l}\text { Stock solution: Internal } \\
\text { standard } \\
\left(3 \text { weeks at } 5^{\circ} \mathrm{C} \pm 3^{\circ} \mathrm{C}\right)\end{array}$ & 0.06 & 0.43 & & 0.91 & 1.34 & \\
\hline
\end{tabular}

CV: coefficient of variation, RE: relative error

Table 4: Stability evaluation

The results indicated that the stability acceptance criteria were met (all mean \%RE values for all tested concentration levels were within $\pm 15 \%$ of the nominal values) [8-10].

This indicates that the analyte was stable in plasma for 16 weeks at $-75^{\circ} \mathrm{C} \pm 5^{\circ} \mathrm{C}$ and during 3 freeze and thaw cycles. In a sample processed at room temperature for 27 hours; in an evaporated sample for 24 hours at room temperature and in an autosampler for 74 hours at room temperature, and in a stock solution for 3 weeks at $5^{\circ} \mathrm{C} \pm 3^{\circ} \mathrm{C}$.

\section{Pharmacokinetic application}

The method was applied to a pharmacokinetic study, in which a single dose of $25 \mathrm{mg}$ of pamabrom was orally administered in combination with $300 \mathrm{mg}$ of paracetamol and $220 \mathrm{mg}$ of naproxen sodium to Mexican female subjects.

As described above, the pharmacokinetics of pamabrom was studied by determining 8-bromotheophylline, the active diuretic ingredient.

Plasma samples were obtained from 12 subjects (aged 19 to 36 years); who participated in a pharmacokinetic study conducted at a clinical unit (IPHARMA, S.A. de C.V. Monterrey, Nuevo León, Mexico).

The study protocol (B19-15) and the informed-consent form were reviewed and approved by an ethics and research committee and authorized by the Federal Commission for Protection against Sanitary Risks (COFEPRIS).

The study was conducted in accordance with the ethical principles of the Declaration of Helsinki and its amendments, as well as the International Conference on Harmonisation for Good Clinical Practice Guideline.

During this study, the subjects fasted for 10 hours overnight before the oral administration of a coated tablet (ANALGEN FEM ${ }^{\bowtie}$ Laboratorios Liomont, S.A. de C.V.) containing pamabrom (25 mg), naproxen sodium (220 mg) and paracetamol (300 mg). 
Blood samples $(6 \mathrm{~mL})$ were drawn from a suitable forearm vein (using an indwelling catheter) at baseline, and at $0.167,0.333,0.5$, $0.667,0.833,1,1.25,1.5,1.75,2,2.5,3,4,5,6,8,10,12,24,48$ and 72 hours after administration. Lithium heparin was used as an anticoagulant.

Blood samples were centrifuged at $3000 \mathrm{rpm}$ for 10 minutes at $5^{\circ} \mathrm{C}$. The plasma was separated and stored at $-65^{\circ} \mathrm{C} \pm 15^{\circ} \mathrm{C} \mathrm{until}$ the samples were transported to Biokinetics (the analytical unit) where they were stored at $-75^{\circ} \mathrm{C} \pm 5^{\circ} \mathrm{C}$ until the time of analysis.

The mean plasma concentration-time curve of 8-bromothophylline is shown in Figure 3 and its corresponding semi-logarithmic plot in Figure 4. The main pharmacokinetic parameters are summarized in Table 5.

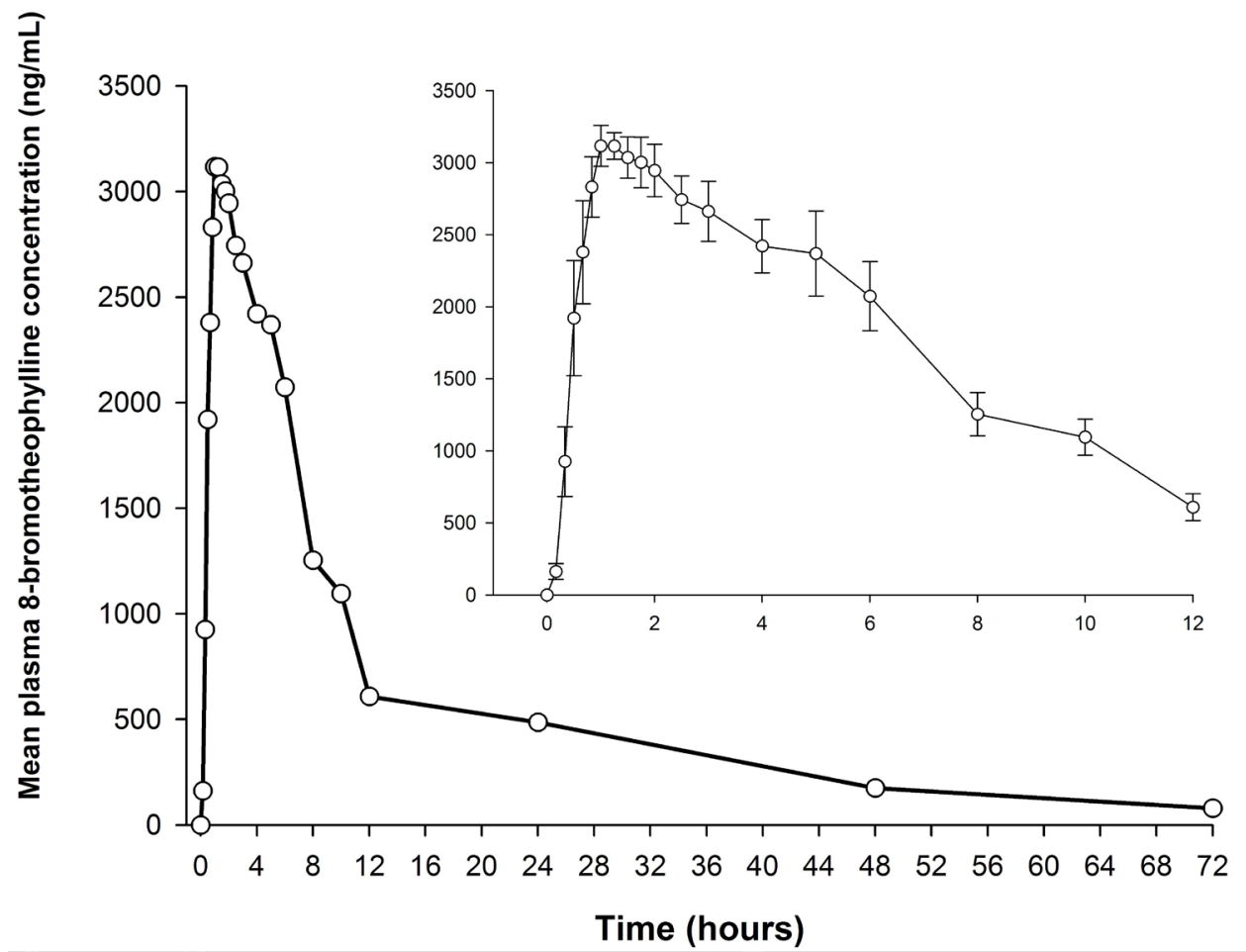

Figure 3: Mean plasma concentration-time curve after a single-dose administration of an oral coated tablet, containing, $25 \mathrm{mg}$ of pamabrom in combination with $220 \mathrm{mg}$ of naproxen sodium and $300 \mathrm{mg}$ of paracetamol (trademark: ANALGEN FEM ${ }^{\circ}$, Laboratorios Liomont, S.A. de C.V.) in healthy Mexican female subjects $(\mathrm{n}=12)$. Pamabrom was determined as 8 -bromotheophylline. Inset: mean $( \pm S E)$ concentrations over the first 12 hours after administration

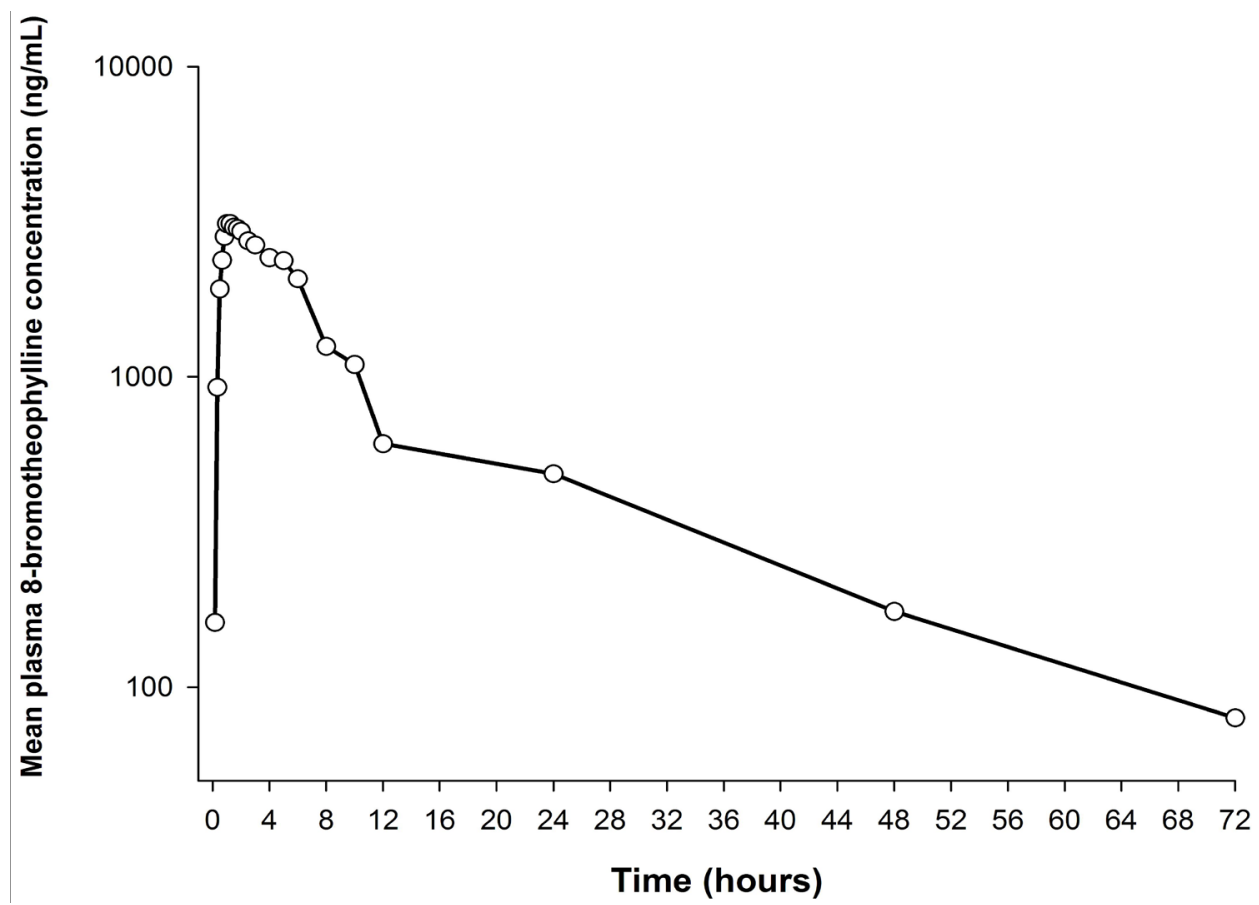

Figure 4: Semi-logarithmic plot of 8-bromotheophylline plasma concentration-time profile after a single-dose administration of an oral coated tablet, containing, $25 \mathrm{mg}$ of pamabrom in combination with $220 \mathrm{mg}$ of naproxen sodium and $300 \mathrm{mg}$ of paracetamol (trademark: ANALGEN FEM ${ }^{\oplus}$, Laboratorios Liomont, S.A. de C.V.) in healthy Mexican female subjects $(n=12)$ 


\begin{tabular}{|c|c|}
\hline Parameter & Mean $\pm \mathrm{SD}$ \\
\hline $\mathrm{C}_{\text {max }}(\mathrm{ng} / \mathrm{mL})$ & $3685.60 \pm 621.35$ \\
\hline $\mathrm{T}_{\text {max }}(\mathrm{h})$ & $1.41 \pm 1.24$ \\
\hline Apparent $_{\mathrm{e}}\left(\mathrm{h}^{-1}\right)$ & $0.05 \pm 0.04$ \\
\hline Apparent t $_{1 / 2}(\mathrm{~h})$ & $21.35 \pm 12.81$ \\
\hline $\mathrm{AUC}_{0-\mathrm{t}}(\mathrm{ng} \cdot \mathrm{h} / \mathrm{mL})$ & $36693.31 \pm 14083.74$ \\
\hline $\mathrm{AUC}_{0-\infty}(\mathrm{ng} \bullet \mathrm{h} / \mathrm{mL})$ & $46210.49 \pm 24196.28$ \\
\hline
\end{tabular}

Table 5: Pharmacokinetic parameters

The present method allowed us to characterize the pharmacokinetic profile of pamabrom in combination with naproxen sodium and paracetamol. The sensitivity of the method was satisfactory because its LLOQ of $20 \mathrm{ng} / \mathrm{mL}$ was $0.54 \%$ of the $\mathrm{C}_{\max }$ (3685.60 $\mathrm{ng} /$ $\mathrm{mL}$ ) of 8-bromotheophylline, which should not be greater than $5 \%$ of the $\mathrm{C}_{\max }$ to be acceptable [8-10].

The pharmacokinetic profile suggested that the plasma concentrations of 8-bromotheophylline decreased in a biexponential or multiexponential manner. In this case, the estimated $\mathrm{k}_{\mathrm{e}}$ and its derived pharmacokinetic parameters $\left(\mathrm{t}_{1 / 2}\right.$ and $\left.\mathrm{AUC}_{0-\infty}\right)$ should be interpreted with caution because the non-compartmental approach is not suitable for determining these parameters under these circumstances. Therefore, further research is needed to clarify this issue.

With this method, it was possible to analyze a total of 158 samples in a single analytical run, including samples from 6 subjects, the system suitability, QCs, and calibration curve samples. The method could be considered convenient for routine application in pharmacokinetic and bioequivalence studies.

\section{Conclusion}

A new sensitive bioanalytical method was developed and validated for the determination of pamabrom, quantified as 8-bromotheophylline using HPLC coupled with UV detection.

This method was successfully applied to a pharmacokinetic study, in which a single dose of $25 \mathrm{mg}$ of pamabrom was administered orally in combination with $300 \mathrm{mg}$ of paracetamol and $220 \mathrm{mg}$ of naproxen sodium to Mexican female subjects.

\section{Acknowledgement}

This research and its publication were supported by Laboratorios Liomont, S.A. de C.V., Mexico City, Mexico. The authors have indicated that they have no conflicts of interest regarding the content of the article.

\section{References}

1. Patil MV, Kolekar GB (2014) Binding of Drug Pamabrom to Human Hemoglobin: Structural and Thermodynamic Characterization Studies. International Journal of Science and Research 3: 3095-109.

2. Toedt J, Koza D, Van Cleef-Toedt K (2005) Chemical composition of everyday products, Greenwood Press, Connecticut, United States.

3. The Society of Obstetricians and Gynecologists of Canada (2005) Primary Dysmenorrhea Consensus Guideline. SOGC Clinical Practical Guidance 169: 1117-29.

4. Ortiz M , Murguía-Cánovas G, Vargas-López LC, Silva R, González-de la Parra M (2016) Naproxen, paracetamol and pamabrom versus paracetamol, pyrilamine and pamabrom in primary dysmenorrhea: a randomized, double-blind clinical trial. Medwave 16: 6587.

5. Palma-Aguirre JA, Villalpando-Hernández J, Novoa-Heckel G, Oliva I, Cariño L, et al. (2009) Bioavailability of two oral-tablet and two oral-suspension formulations of naproxen sodium/paracetamol (acetaminophen): Single-dose, randomized, open-label, two-period crossover comparisons in healthy Mexican adult subjects. Clinical Therapeutics 31: 399-410.

6. Li JC, Ma T, Huo Q, Zhang JD, Dong HJ, et al. (2010) Investigation on the pharmacokinetics of compound acetaminophen and pamabrom tablets in female healthy volunteers. Chinese J Hosp Pharm 4: 009.

7. Wang H, Jin X, Zhao L, Chen J, Lü L, et al. (2010) Determination of paracetamol and pamabrom in human plasma and urine by LC/MS method. Pharma Care Res 10: 198-201.

8. COFEPRIS, Federal Commission for the Protection against Sanitary Risks (2013) Official Mexican Standard NOM 177-SSA1-2013: Tests and procedures to prove that a medication is interchangeable [in Spanish]: General Directorate of Standards. Mexico City, Mexico.

9. Committee for Medicinal Products for Human Use (2011) Guideline on bioanalytical method validation. European Medicines Agency.

10. Center for Drug Evaluation and Research, Center for Veterinary Medicine (2001) Guidance for Industry. Bioanalytical method validation. Food and Drug Administration. 


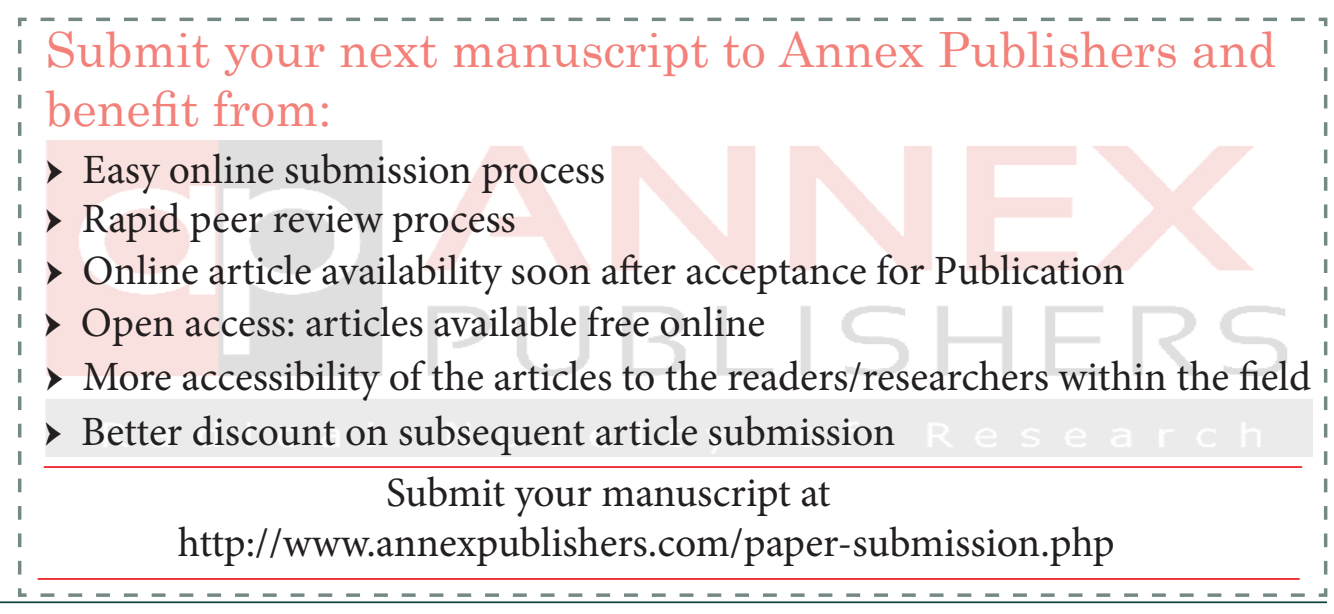

